\title{
BMJ Open Parallel multicentre randomised trial of a clinical trial question prompt list in patients considering participation in phase 3 cancer treatment trials
}

\author{
Martin H N Tattersall, ${ }^{1,2}$ Michael Jefford, ${ }^{3,4}$ Andrew Martin, ${ }^{5}$ lan Olver, ${ }^{6}$ \\ John F Thompson, ${ }^{7}$ Richard F Brown, ${ }^{8}$ Phyllis N Butow ${ }^{9}$
}

To cite: Tattersall MHN, Jefford M, Martin A, et al. Parallel multicentre randomised trial of a clinical trial question prompt list in patients considering participation in phase 3 cancer treatment trials. $B M J$ Open 2017:7:e012666. doi:10.1136/bmjopen-2016012666

- Prepublication history and additional material is available. To view please visit the journal (http://dx.doi.org/ 10.1136/bmjopen-2016012666).

Received 16 June 2016 Revised 22 November 2016 Accepted 9 February 2017

CrossMark

For numbered affiliations see end of article.

Correspondence to Professor Martin HN Tattersall; martin.tattersall@ sydney.edu.au

\section{ABSTRACT}

Objective: To evaluate the effect of a clinical trial question prompt list in patients considering enrolment in cancer treatment trials.

Setting: Tertiary cancer referral hospitals in three state capital cities in Australia.

Participants: 88 patients with cancer attending three cancer centres in Australia, who were considering enrolment in phase 3 treatment trials, were invited to enrol in an unblinded randomised trial of provision of a clinical trial question prompt list (QPL) before consenting to enrol in the treatment trial.

Interventions: We developed and pilot tested a targeted QPL for patients with cancer considering clinical trial participation (the clinical trial QPL). Consenting patients were randomised to receive the clinical trial QPL or not before further discussion with their oncologist and/or trial nurse about the treatment trial.

Primary and secondary outcomes: Questionnaires were completed at baseline and within 3 weeks of deciding on treatment trial participation. Main outcome measure: scores on the Quality of Informed Consent questionnaire (QuIC).

Results: 88 patients of 130 sought for the study were enrolled (43 males), and 45 received the clinical trial QPL. $49 \%$ of trials were chemotherapy interventions for patients with advanced disease, $35 \%$ and $16 \%$ were surgical adjuvant and radiation adjuvant trials respectively. 70 patients completed all relevant questionnaires. 28 of 43 patients in the control arm compared with 39 of 45 patients receiving the clinical trial QPL completed the QuIC ( $p=0.0124)$. There were no significant differences in the QulC scores between the randomised groups (QulC part A $p=0.08$ and QulC part $B \quad p=0.92$ ). There were no differences in patient satisfaction with decisions or in anxiety levels between the randomised groups.

Conclusions: Use of a question prompt list did not significantly change the QulC scores in this randomised trial. ANZCTR 12606000214538 prospectively registered 31/5/2006.

Trial registration number: Results, ACTRN12606000214538.

\section{Strengths and limitations of this study}

- The clinical trial question prompt list contained 51 questions grouped under 10 headings.

- The Quality of Informed Consent questionnaire (QuIC) is widely used to measure clinical trial participants' actual and perceived understanding of cancer clinical trials.

- The trial was stopped prematurely due to low accrual rates and on the advice of an independent data monitoring committee.

- Participants had only a few minutes to review the clinical trial question prompt list (QPL) before continuing discussion about the randomised cancer treatment trial.

- Information about the duration of the informed consent discussion in the trial is not available.

- The time patients receiving QPL list had to review the QPL before continuing the discussion about the cancer treatment is not available.

\section{INTRODUCTION}

Surveys of the public have found widespread support for the concept of clinical trials as an important and ethical means of developing improved medical care. However, only a small percentage of eligible patients are recruited to clinical trials in many institutions that promote clinical trial participation.

A significant proportion of non-trial participation is explained by patient refusal. ${ }^{1}$ Reasons for trial refusal by eligible patients include concerns regarding experimentation and uncertainty and loss of control over treatment decisions. Even when patients agree to participate, they frequently do not understand basic components of the trial that they have consented to enter. ${ }^{2}{ }^{3}$ In the UK Jenkins et $a l^{4}$ audiotaped discussions between oncologists and patients during which consent was being obtained for a randomised clinical trial. In most, the concept of the trial was introduced by describing 
uncertainty about treatment decisions. The word randomisation was mentioned in 51 consultations $(62.2 \%)$. The median duration of 'consent' interviews was $<15$ min and most patients signed the consent document at the first consultation at which the clinical trial was discussed.

Brehaut et $a \check{l}^{6}$ argue that the existing approach to obtaining informed consent for clinical research may be improved by using decision aids. Juraskova et $a l^{7}$ reported successful piloting of a decision aid to assist women considering participation in a breast cancer prevention trial. Spiegle $e t a l^{8}$ performed a systematic review to identify alternative types of decision support interventions (DSIs) for cancer treatment and a meta-analysis to compare the effectiveness of DSIs compared with patient decision aids. The study showed that the effectiveness of other DSIs, including question prompt list (QPLs) and audio recordings of the consultation, is similar to patient decision aids. This finding is important because less complex DSIs such as a targeted QPL may be all that is necessary to achieve similar outcomes as patient decision aids for cancer treatment. QPLs have been shown to increase question asking in patients with cancer. $^{9} 10$

The Quality of Informed Consent questionnaire (QuIC) was designed to measure participants' actual (objective) and perceived (subjective) understanding of cancer clinical trials. Joffe $e t a l^{11}$ derived 13 independent domains of informed consent and wrote one or more questions to measure participants' objective and subjective understanding of their clinical trials. After feedback from pilot testing and input from expert panels, the QuIC was sent to adult patients with cancer enrolled in phase 1, 2 and 3 clinical trials. Test-retest reliability was good, as was face and content validity. The QuIC took an average of $7.2 \mathrm{~min}$ to complete.

Joffe $e t a l^{2}$ reported the use of the QuIC to measure the quality of understanding among 207 cancer clinical trial participants in Boston who had signed a clinical trial consent form a median of 16 days earlier. Almost half of the consent discussions had lasted 1 hour. The consent form was signed a median of 6 days after the initial discussions about the trial and a quarter signed during the first consultation. There was considerable variation in the proportion of correct answers across individual questions in the QuIC.

Bergenmar et $a l^{12}$ used the QuIC to survey 282 patients who had been informed in Swedish about a phase 2 or phase 3 trial and had signed a consent form. The patients were asked about the duration of the consent discussion. Thirty-nine patients (14\%) reported the duration of the consent discussion was $<15 \mathrm{~min}, 139$ patients $(50 \%)$ responded between 15 and $30 \mathrm{~min}$, and 50 patients $(11 \%)$ between 45 and $60 \mathrm{~min}$. The proportion of correct responses to the 16 items applicable to all patients, irrespective of trial phase was presented. High levels of knowledge $(>80 \%)$ were found for seven items, and five items were responded to correctly by
$50-80 \%$ of the patients. In total, $<50 \%$ responded correctly to four items, namely risks related to the trial, the unproven nature of the trial and issues about insurances in connection to participating in the trial.

We used the QuIC to survey patients with cancer in Sydney and Melbourne who had been approached to participate in a clinical trial. The mean score on part A of the QuIC among 100 patients studied in Sydney was 76.8. ${ }^{13}$ In 72 patients with cancer studied in Melbourne, the median objective knowledge score was $77.6 / 100$, and perceived (subjective) understanding (QuIC part B) score was 91.5. ${ }^{3}$ Some questions were answered particularly poorly. Higher knowledge score (QuIC part A) was associated with English as a first language. Calculation of the summary score questions included is presented in http://jnci.oxfordjournals.org/content/93/2/139.full. This also shows the questions that are not scored for particular phase trials.

We developed a targeted QPL for clinical trials in order to identify questions which might facilitate patient participation in clinical trial discussions with their oncologist and clinical trial nurse. ${ }^{14}$ We conducted a series of focus groups with patients with cancer and their carers. The focus groups were audio-taped and transcribed. The transcripts were analysed using rigorous qualitative methodology. The final draft of the QPL was pilot tested to evaluate content validity, and acceptability and perceived efficacy in satisfying information needs about clinical trials needs and achieving involvement preference using a sample of 10 patients with cancer considering participation in a phase 3 clinical trial at each of the participating institutions. The clinicians, oncologists and clinical research nurses were encouraged to endorse and refer to the QPL during their discussion. Feedback from these patient/clinician cohorts informed the final version of the clinical trial QPL. The final version of the clinical trial QPL used in the randomised trial includes 51 questions grouped under 10 headings is presented in figure 1 .

The aims of this study were to determine whether providing patients who are considering clinical trial participation with a QPL about clinical trials enhances: (1) the patient's quality of understanding of the cancer clinical trial; (2) patient achievement of his or her involvement/ participation preference, (3) patient satisfaction with the informed consent to treatment decision-making process and (4) oncologist and research nurse satisfaction with the clinical trial discussion and decision-making process.

We hypothesised that patients with cancer receiving a clinical trial QPL which was endorsed by the oncologist and trial nurse prior to deciding whether to participate in a randomised cancer clinical trial compared with patients not receiving this intervention would have a higher mean knowledge score in the informed consent questionnaire (QuIC part A) (primary outcome); have enhanced achievement of their information and involvement/participation preference; and, be more satisfied with the informed consent and decision-making process. 


\begin{tabular}{|c|c|c|c|}
\hline 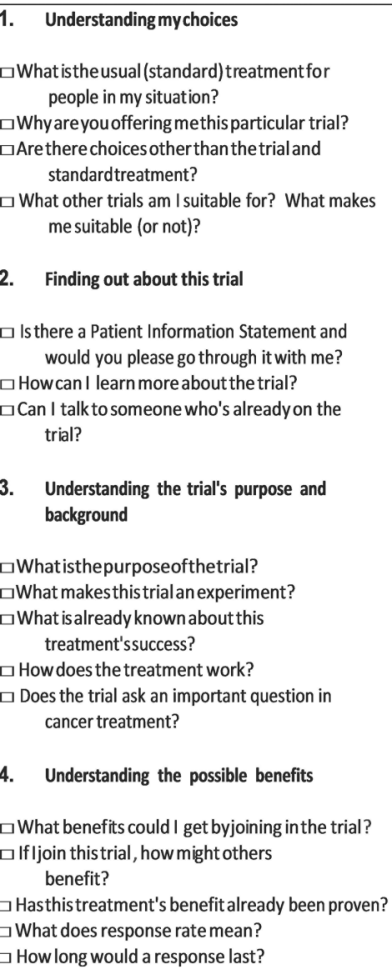 & $\begin{array}{l}\text { पHowdoyou measure response? What is meant } \\
\text { by "measurable disease"? } \\
\text { 5. Understanding the possible risks } \\
\square \text { What arethe risks of taking the new } \\
\text { treatment? } \\
\square \text { Could there be any long term or permanent } \\
\text { changes from the treatment? } \\
\square \text { Are thereanyserious or rareside effects I should } \\
\text { know about? } \\
\square \text { Whom can Icall if something goes } \\
\text { wrong? } \\
\square \text { If Iget a side effect or injury because of being in } \\
\text { thetrial, will Iget compensation? } \\
\text { 6. The differences between going on the trial \& } \\
\text { having standard treatment } \\
\square \text { If lenter the clinical trial, will I need to have extra } \\
\text { tests, go to more clinics and will itcost me any } \\
\text { money? (extra parking, extra medication) How } \\
\text { is this different from standard treatment? } \\
\square \text { Will there beside effectson the trial which Iwon't } \\
\text { get on thestandard treatment? } \\
\square \text { Wherewilltreatment forthe trial be given? Is } \\
\text { that somewhere different from standard } \\
\text { treatment? } \\
\square \text { Can Ihavethe trial treatment at my local } \\
\text { hospital? } \\
\text { 7. Understanding how the trial is being carried out } \\
\square \text { Is the newtreatment only available through } \\
\text { joining the trial? } \\
\square \text { Howlong has the trial been going on? } \\
\square \text { How many hospitals are involved? }\end{array}$ & 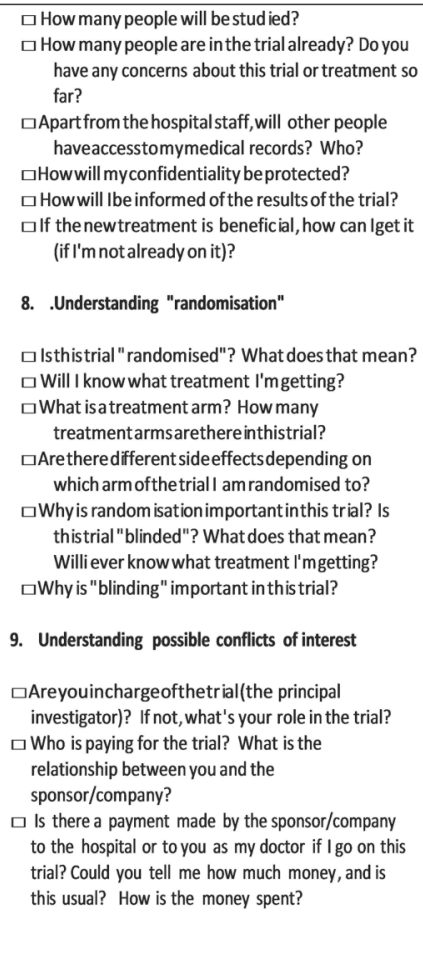 & $\begin{array}{l}\text { 10.Understanding my right to join or not to joi } \\
\text { trial } \\
\square \text { Will you still treat me if Idecide not togo o } \\
\text { trial? } \\
\square \text { Do I have time to think about whether to g } \\
\text { the trial (a day or two, or a week)? } \\
\square \text { If Idotake some time to decide will that aff } \\
\text { how well the treatment works? } \\
\square \text { If I join the trial, but later change my mind } \\
\text { how can Istop? Will this make a difference } \\
\text { my treatment? } \\
\square \text { If I join the trial, will Ilose out on any new } \\
\text { treatment opportunities (e.g. another trial, } \\
\text { standard treatment later)? } \\
\square \text { Can I still use alternative therapies if Igo on } \\
\text { trial? }\end{array}$ \\
\hline
\end{tabular}

Figure 1 Questions you may wish to ask your doctor about clinical trials. This question prompt list is intended to help you to make a decision about participating in a cancer clinical trial. It provides you with some questions that you might like to think about and ask your doctor now or later.

We also hypothesised that the intervention would not reduce clinical trial participation.

\section{METHODS}

All patients invited to participate in a randomised cancer treatment clinical trial at three participating cancer centres were eligible for the study evaluating use of the clinical trial QPL unless the cancer treatment protocol excluded patients entered in a second randomised trial. Eligible patients were approached by a research nurse prior to their written consent to the cancer treatment trial being sought and invited to participate in the evaluation of the clinical trial question prompt list. After their written consent had been obtained, patients completed a questionnaire containing measures of information and involvement preferences, ${ }^{15} 16$ their attitudes to clinical trials ${ }^{17}$ and their anxiety level ${ }^{18}$ (see online supplementary appendix 1 ).

A randomisation sequence was generated by an independent service. Patients were randomised by opening a numbered blank envelope containing the treatment group allocation: to receive or not receive the clinical trial QPL. Patients in the control group continued their discussion with the oncologist/research nurse about the clinical treatment trial. Patients randomised to receive the clinical trial QPL had at least a few minutes to review it before continuing discussion with their oncologist and/or clinical research nurse about the cancer trial proposed. During this latter discussion the clinicians specifically referred to the QPL and encouraged patients to review the list of questions. Thus participants were not blinded to intervention assignment; however, data entry personnel were blinded. There was no control of QPL exposure time nor was the time documented. There was no researcher control of items in the QPL raised by the patient or clinician.

After the decision about cancer treatment clinical trial participation, and within 3 weeks, patients were asked to complete the $\mathrm{QuIC}^{2}$ and questionnaires measuring anxiety, ${ }^{18}$ their satisfaction with the consent discussion and decision making ${ }^{19}$ and achievement of their information and involvement preferences. ${ }^{20}$ Clinician satisfaction with the informed consent process was measured using an adapted form of an existing seven-item scale measuring physician satisfaction with the decisionmaking process $^{21}{ }^{22}$ (see online supplementary appendix 2).

The primary outcome measure was the QuIC. Part A of this scale contains questions covering 13 domains which are summed to produce a total score capped at 100. The authors of the QuIC reported a mean total score of 79.7 and SD of 7.7 on part A of the scale. An improvement of understanding of one entire domain score is considered to be a clinically significant improvement. A sample of 130 patients was sought for the study to have $80 \%$ power at the $5 \%$ two-sided level of significance to detect a clinically meaningful difference. 
Table 1 Patient demographic, randomisation group, attitude to clinical trials

\begin{tabular}{|c|c|c|}
\hline & Intervention & Control \\
\hline \multicolumn{3}{|l|}{ Age } \\
\hline $\mathrm{N}$ & 45 & 43 \\
\hline Mean & 57 & 56.9 \\
\hline Median & 58 & 60 \\
\hline SD & 13.2 & 14.5 \\
\hline Minimum & 28 & 22 \\
\hline Maximum & 85 & 84 \\
\hline \multicolumn{3}{|l|}{ Gender } \\
\hline Female & $25(56 \%)$ & $20(47 \%)$ \\
\hline \multicolumn{3}{|l|}{ Marital status } \\
\hline Never married & $5(11 \%)$ & $7(16 \%)$ \\
\hline Married/de facto & $30(67 \%)$ & $30(70 \%)$ \\
\hline Widowed & $2(4 \%)$ & $3(7 \%)$ \\
\hline Divorced/separated & $7(16 \%)$ & $3(7 \%)$ \\
\hline Other & $1(2 \%)$ & $0(0 \%)$ \\
\hline \multicolumn{3}{|l|}{ Education } \\
\hline Year 10 or below & $18(41 \%)$ & $16(37 \%)$ \\
\hline Year 12 & $6(14 \%)$ & $12(28 \%)$ \\
\hline Certificate/diploma & $10(23 \%)$ & $8(19 \%)$ \\
\hline University degree & $5(11 \%)$ & $7(16 \%)$ \\
\hline Higher degree/postgraduate & $5(11 \%)$ & $0(0 \%)$ \\
\hline \multicolumn{3}{|l|}{ Country of birth } \\
\hline Australia & 38 (84\%) & $40(93 \%)$ \\
\hline Other & $3(7 \%)$ & $0(0 \%)$ \\
\hline Croatia & $1(2 \%)$ & $0(0 \%)$ \\
\hline Italy & $0(0 \%)$ & $1(2 \%)$ \\
\hline Hungary & $1(2 \%)$ & $0(0 \%)$ \\
\hline UK & $1(2 \%)$ & $1(2 \%)$ \\
\hline New Zealand & $0(0 \%)$ & $1(2 \%)$ \\
\hline Poland & $1(2 \%)$ & $0(0 \%)$ \\
\hline \multicolumn{3}{|l|}{ Hospital } \\
\hline $\mathrm{RPAH}$ & $26(58 \%)$ & $25(58 \%)$ \\
\hline PETER MAC & $15(33 \%)$ & $13(30 \%)$ \\
\hline Royal Adelaide & $4(9 \%)$ & $5(12 \%)$ \\
\hline \multicolumn{3}{|l|}{ Trial Context } \\
\hline $\begin{array}{l}\text { Chemotherapy for advanced } \\
\text { disease }\end{array}$ & 22 & 24 \\
\hline Adjuvant surgery & 12 & 15 \\
\hline Adjuvant radiation & 8 & 7 \\
\hline \multicolumn{3}{|c|}{ Specialist who was involved in the trial discussion } \\
\hline Medical oncologist & $20(44 \%)$ & $23(53 \%)$ \\
\hline Surgeon & $16(36 \%)$ & $15(35 \%)$ \\
\hline Radiation oncologist & $6(13 \%)$ & $4(9 \%)$ \\
\hline Medical + radiation oncologist & $3(7 \%)$ & $1(2 \%)$ \\
\hline \multicolumn{3}{|l|}{ Positive attitude } \\
\hline $\mathrm{N}$ & 45 & 43 \\
\hline Mean & 14 & 13.4 \\
\hline SD & 3 & 4.4 \\
\hline Median & 15 & 15 \\
\hline Minimum & 8 & 0 \\
\hline Maximum & 18 & 18 \\
\hline \multicolumn{3}{|l|}{ Neqative Attitude } \\
\hline $\mathrm{N}$ & 45 & 43 \\
\hline Mean & 4.9 & 4.3 \\
\hline $\mathrm{SD}$ & 2.1 & 2.6 \\
\hline Median & 5 & 4 \\
\hline Minimum & 0 & 0 \\
\hline Maximum & 10 & 10 \\
\hline
\end{tabular}

Table 1 Continued

\begin{tabular}{lcc}
\hline & Intervention & Control \\
\hline Clinical trial knowledge score & & \\
N & 45 & 43 \\
Mean & 4 & 3.6 \\
SD & 1.8 & 2.1 \\
Median & 4 & 4 \\
Minimum & 0 & 0 \\
Maximum & 7 & 7 \\
Withdrawal/missing & & \\
No & $40(89 \%)$ & $30(70 \%)$ \\
Did not complete & $0(0 \%)$ & $3(7 \%)$ \\
questionnaire & & \\
Second questionnaire not & $5(11 \%)$ & $10(23 \%)$ \\
$\quad$ completed & \\
\hline Peter Mac, Peter MacCallum Cancer Centre; RPAH, Royal Prince \\
Alfred Hospital.
\end{tabular}

The trial accrued slowly and was stopped after 88 patients had been randomised on the advice of an independent data monitoring committee who determined that the probability of detecting a clinically meaningful difference with continued recruitment was very low (ie, the conditional power at this point in the study was well under 20\%).

Eighty-eight patients were enrolled of whom 43 were males and 45 received the clinical trial QPL. Fifty-one were recruited from Royal Prince Alfred Hospital, 28 from Peter MacCallum Cancer Centre and nine from Royal Adelaide Hospital. Table 1 presents demographic and disease details including the clinical treatment trial intervention, participating hospital and randomisation group. Patients' attitudes to clinical trials, ${ }^{15}$ clinical trial knowledge score, ${ }^{21} 22$ and status of completed questionnaires are also presented. Participants were balanced for gender, marital status and education level. Seventy patients completed all relevant questionnaires, but 13 in the control arm and five in the intervention arm did not complete the first and/or second questionnaires (figure 2).

Table 2 presents the results of the QuIC scores, and the Spielberger State Anxiety Inventory. ${ }^{18}$ Twenty-eight of 43 patients in the control arm compared with 39 of 45 receiving the clinical trial QPL completed the informed consent questionnaire $(\mathrm{p}=0.02)$. There were no significant differences in the QuIC scores between the randomised groups (QuIC part A p=0.08 and QuIC part $\mathrm{B} p=0.92)$. We tested whether patient age or gender modified the effect of the QPL on the QuIC, and found no statistical evidence for this.

There was no difference in anxiety between the randomised groups.

Table 3 presents the results of patient satisfaction with the decision scores. There is no difference between the randomised groups in these results.

Table 4 presents the results of physician satisfaction with the consultation and with decision scores. There is no difference between the randomised groups in these results. 


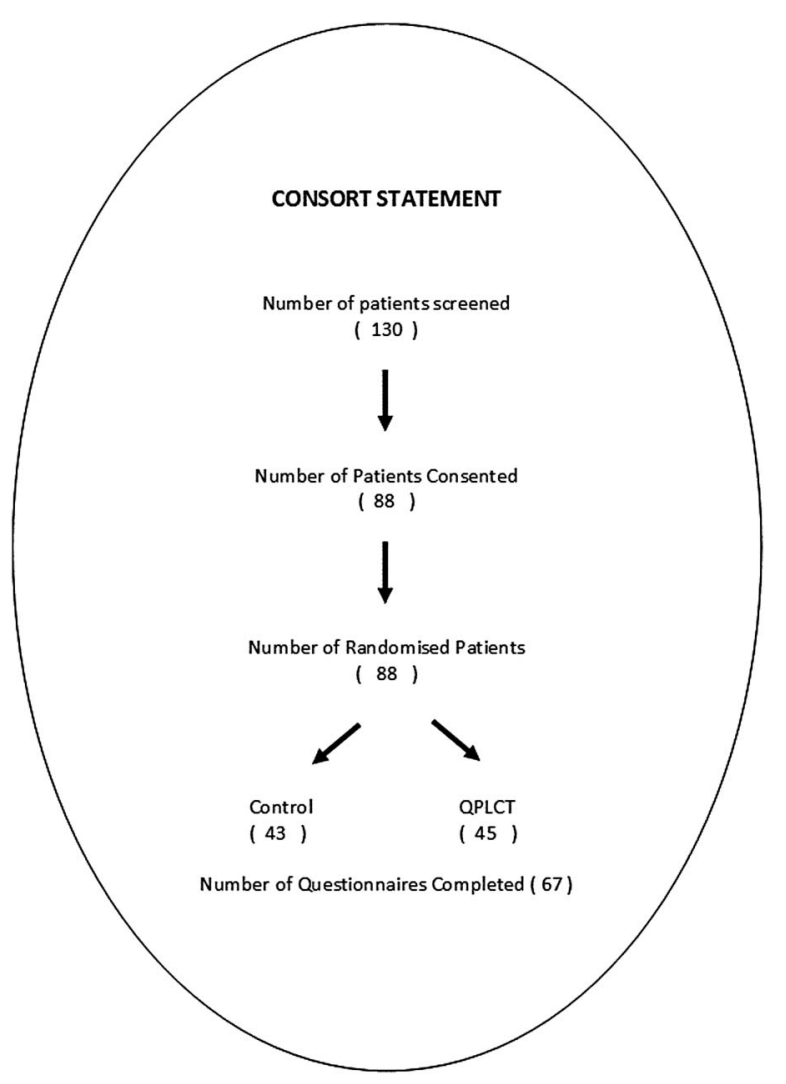

Figure 2 Participant flow diagram.

\section{DISCUSSION}

Use of the clinical trial QPL did not significantly change patient knowledge scores measured by the QuIC. The percentage of patients in the control arm completing the QuIC was significantly reduced compared with the intervention group $(\mathrm{p}=0.02)$. There was a trend towards lower knowledge scores (QuIC part A) in the intervention group compared with control $(\mathrm{p}=0.08)$. The reason for this is unknown. Patients in the control group who actually completed the assessment achieved favourable results. We hypothesise that those in the control group who comprised 28 of 43 patients in the control arm constituted a self-selected cohort of patients who were more engaged in the clinical trial process.

We have no information about the duration of the consent interviews in our trial, but it is likely that use of the clinical trial QPL extended the consent interview by a few minutes. Patients only had the QPL for a few minutes before continuing with the clinical trial consent discussion so the 'dose' of the QPL may be low, and therefore not effective. Physician endorsement of QPL use by the patient in other contexts has been an important contributor to the efficacy of QPLs. ${ }^{23}{ }^{24}$ As QPLs have previously demonstrated benefit, it may have been these exposure and endorsement factors that prevented efficacy of the clinical trial QPL in this instance.

The patients in our trial all consented to participate in the informed consent trial at the first consultation when trial participation was sought. This finding differs from the experience reported by Joffe $e t a l^{2}$ where the consent form for the treatment trial was signed a median of 6 days after the initial discussion about the trial, and only $28 \%$ consented at the first consultation. There is great variation in the interval from considering participation in a clinical trial to consenting to enrol in the trial. We do not know when patients consented to participate in the cancer treatment trial but patients were asked to complete the QuIC within 3 weeks after the decision about cancer trial participation had been made.

Stryker et $a l^{25}$ studied the factors associated with informed consent, patient satisfaction, and decisional

\begin{tabular}{|c|c|c|c|c|}
\hline Measure & Intervention & Control & Difference $(95 \% \mathrm{Cl})$ & p Value* \\
\hline \multicolumn{5}{|c|}{ QulC part A summary } \\
\hline $\mathrm{N}$ & 39 & 28 & & \\
\hline Mean & 75.5 & 79.9 & $4.5(95 \% \mathrm{Cl}-0.5$ to 9.5$)$ & 0.080 \\
\hline SD & 9.9 & 10.4 & & \\
\hline Minimum & 53.8 & 51.9 & & \\
\hline Maximum & 94.2 & 100 & & \\
\hline \multicolumn{5}{|c|}{ QulC part B summary } \\
\hline $\mathrm{N}$ & 39 & 28 & & \\
\hline Mean & 88.4 & 88.1 & $-0.3(95 \% \mathrm{Cl}-6.1$ to 5.5$)$ & 0.920 \\
\hline SD & 12.1 & 11.4 & & \\
\hline Minimum & 51.8 & 64.3 & & \\
\hline Maximum & 100 & 100 & & \\
\hline \multicolumn{5}{|c|}{ Spielberger State Anxiety Inventory (follow-up) } \\
\hline $\mathrm{N}$ & 38 & 26 & & \\
\hline Mean & 34.815 & 37.153 & $2.3(95 \% \mathrm{Cl}-3.7$ to 8.3$)$ & 0.438 \\
\hline SD & 10.8 & 13.1 & & \\
\hline Minimum & 20 & 20 & & \\
\hline Maximum & 63 & 66 & & \\
\hline
\end{tabular}


Table 3 Patient satisfaction with decision scores

\begin{tabular}{|c|c|c|c|}
\hline Measure & Intervention & Control & p Value* \\
\hline \multicolumn{4}{|l|}{ Adequately informed } \\
\hline Disagree strongly & $0(0 \%)$ & $1(4 \%)$ & \\
\hline I disagree & $1(3 \%)$ & $0(0 \%)$ & \\
\hline Neutral & $2(5 \%)$ & $2(7 \%)$ & \\
\hline Agree & $20(51 \%)$ & $12(43 \%)$ & \\
\hline Agree strongly & $16(41 \%)$ & $13(46 \%)$ & \\
\hline Total & 39 & 28 & 0.6315 \\
\hline \multicolumn{4}{|l|}{ Best decision } \\
\hline Disagree strongly & $0(0 \%)$ & $1(4 \%)$ & \\
\hline I disagree & $1(3 \%)$ & $0(0 \%)$ & \\
\hline Neutral & $3(8 \%)$ & $3(11 \%)$ & \\
\hline I agree & $13(33 \%)$ & $10(36 \%)$ & \\
\hline Agree strongly & $22(56 \%)$ & $14(50 \%)$ & \\
\hline Total & 39 & 28 & 0.6575 \\
\hline \multicolumn{4}{|c|}{ Consistent with values } \\
\hline Disagree strongly & $0(0 \%)$ & $1(4 \%)$ & \\
\hline Neutral & $5(13 \%)$ & $3(11 \%)$ & \\
\hline I agree & $17(35 \%)$ & $12(43 \%)$ & \\
\hline Agree strongly & $16(42 \%)$ & $12(43 \%)$ & \\
\hline Total & 38 & 28 & 0.6935 \\
\hline \multicolumn{4}{|l|}{ Carry out decision } \\
\hline Disagree strongly & $0(0 \%)$ & $1(4 \%)$ & \\
\hline Neutral & $2(5 \%)$ & $0(0 \%)$ & \\
\hline I agree & $17(46 \%)$ & $14(50 \%)$ & \\
\hline Agree strongly & $18(49 \%)$ & $13(46 \%)$ & \\
\hline Total & 37 & 28 & 0.4063 \\
\hline \multicolumn{4}{|c|}{ I am satisfied this was my decision to make } \\
\hline Disagree strongly & $0(0 \%)$ & $1(4 \%)$ & \\
\hline Neutral & $2(5 \%)$ & $1(4 \%)$ & \\
\hline I agree & $13(33 \%)$ & $14(50 \%)$ & \\
\hline Agree strongly & $24(62 \%)$ & $12(43 \%)$ & \\
\hline Total & 39 & 28 & 0.3002 \\
\hline \multicolumn{4}{|c|}{ I am satisfied with my decision } \\
\hline Disagree strongly & $0(0 \%)$ & $1(4 \%)$ & \\
\hline Neutral & $4(11 \%)$ & $3(11 \%)$ & \\
\hline I agree & $14(37 \%)$ & $11(39 \%)$ & \\
\hline Agree strongly & $20(53 \%)$ & $13(46 \%)$ & \\
\hline Total & 38 & 28 & 0.6806 \\
\hline
\end{tabular}

regret in 87 patients who were eligible to participate in 12 selected phase 1, 2 and 3 clinical trials. They found that patients who enrolled in clinical trials quickly, may not believe they fully understand the implications of trial participation and ultimately regret their decision to participate. However, there was no relationship between timing of consent and decisional regret.

Limitations of the study include the low accrual rate, the imbalance in completion of the QuIC in the randomised groups and the brief exposure to the clinical trial QPL. Future studies of clinical trial question prompt lists should document the duration of the consent interview, the time taken for consent to be given, and consideration of when is the optimal time for patient understanding of their clinical trial to be sought.
Table 4 Clinical satisfaction with the consent consultation and with decision scores

Intervention Control p Value*

I am satisfied that I provided enough information about the treatment options

$\begin{array}{lccc}\text { Strongly disagree } & 1(2 \%) & 2(6 \%) & \\ \text { Not sure } & 1(2 \%) & 1(3 \%) & \\ \text { Agree } & 21(51 \%) & 21(58 \%) & \\ \text { Strongly agree } & 18(44 \%) & 12(33 \%) & \\ \text { Total } & 41 & 36 & 0.77\end{array}$

I am satisfied that I clearly communicated the clinical trial and treatment options

Strongly disagree $1(2 \%) \quad 1(3 \%)$

Not sure $\quad 2(5 \%) \quad 3(8 \%)$

Agree $20(49 \%) \quad 21(58 \%)$

Strongly agree $18(44 \%) \quad 11(31 \%)$

$\begin{array}{llll}\text { Total } & 41 & 36 & 0.68\end{array}$

I am satisfied that I involved the patient in the

decision-making process

$\begin{array}{lcc}\text { Strongly disagree } & 1(2 \%) & 1(3 \%) \\ \text { Not sure } & 2(5 \%) & 2(6 \%) \\ \text { Agree } & 21(51 \%) & 21(58 \%) \\ \text { Strongly agree } & 17(41 \%) & 12(33 \%) \\ \text { Total } & 41 & 36\end{array}$

The patient understood the clinical trial being proposed

Strongly disagree $1(2 \%) \quad 1(3 \%)$

Disagree $\quad 0(0 \%) \quad 1(3 \%)$

Not sure $\quad 1(2 \%) \quad 3(8 \%)$

Agree $\quad 26(63 \%) \quad 25(69 \%)$

Strongly agree $\quad 13(32 \%) \quad 6(17 \%)$

$\begin{array}{llll}\text { Total } & 41 & 36 & 0.33\end{array}$

Overall, I am satisfied with the decision-making process for this patient

\begin{tabular}{lccc} 
Strongly disagree & $2(5 \%)$ & $1(3 \%)$ & \\
Disagree & $1(2 \%)$ & $0(0 \%)$ & \\
Not sure & $2(5 \%)$ & $5(14 \%)$ & \\
Agree & $22(54 \%)$ & $23(64 \%)$ & \\
Strongly agree & $14(34 \%)$ & $7(19 \%)$ & \\
Total & 41 & 36 & 0.32 \\
\hline
\end{tabular}

*Fisher's exact test.

Author affiliations

${ }^{1}$ Sydney Cancer Centre, Royal Prince Alfred Hospital, Camperdown, New South Wales, Australia

${ }^{2}$ Department of Cancer Medicine, University of Sydney, Camperdown, New South Wales, Australia

${ }^{3}$ Department of Medical Oncology, Peter MacCallum Cancer Centre,

Melbourne, Victoria, Australia

${ }^{4}$ Sir Peter MacCallum Department of Oncology, The University of Melbourne, Melbourne, Victoria, Australia

${ }^{5}$ National Health and Research Council, Clinical Trials Centre, University of Sydney, Camperdown, New South Wales, Australia

${ }^{6}$ Royal Adelaide Hospital, North Terrace, Adelaide, South Australia, Australia ${ }^{7}$ Melanoma Institute Australia, Royal Prince Alfred Hospital and the University of Sydney, Camperdown, New South Wales, Australia

${ }^{8}$ Department of Health Behaviour and Policy, School of Medicine, Virginia Commonwealth University, Richmond, Virginia, USA

${ }^{9}$ Centre for Medical Psychology and Evidence-Based Decision-Making, School of Psychology, University of Sydney, Camperdown, New South Wales, Australia 
Acknowledgements We are grateful to Professor Martin Stockler and Professor Val Gebski who were members of the Independent Data Monitoring Committee.

Contributors MHNT substantially contributed to the conception and design of the work and contributed in drafting the work or revising it critically for important intellectual content, and approved the final version published; the agreement to be accountable for all aspects of the work in ensuring that questions related to the accuracy or integrity of any part of the work are appropriately investigated and resolved. MJ substantially contributed to the conception and design of the work contributed in drafting the work or revising it critically for important intellectual content, and approved the final version published; the agreement to be accountable for all aspects of the work in ensuring that questions related to the accuracy or integrity of any part of the work are appropriately investigated and resolved. AM substantially contributed to the acquisition of analysis and interpretation of data and contributed in drafting work critically for important intellectual content and approved the final version published; the agreement to be accountable for all aspects of the work in ensuring that questions related to the accuracy or integrity of any part of the work are appropriately investigated and resolved. I0 substantial contributed to the conception and design of the work. Drafting the work or revising it critically for important intellectual content and approved the final version published. Agreement to be accountable for all aspects of the work in ensuring that questions related to the accuracy or integrity of any part of the work are appropriately investigated and resolved. JFT substantially contributed to the conception and design of the work and contributed in rafting the work or revising it critically for important intellectual content and approved the final version published; agreement to be accountable for all aspects of the work in ensuring that questions related to the accuracy or integrity of any part of the work are appropriately investigated and resolved. RFB substantially contributed to the conception and analysis of interpretation of data and approved the final version published; agreement to be accountable for all aspects of the work in ensuring that questions related to the accuracy or integrity of any part of the work are appropriately investigated and resolved. PNB substantially contributed to the conception and design of the work and contributed in drafting the work or revising it critically for important intellectual content and approved the final version published; agreement to be accountable for all aspects of the work in ensuring that questions related to the accuracy or integrity of any part of the work are appropriately investigated and resolved.

Funding This work was supported by the Cancer Councils of New South Wales, Victoria and South Australia (grant number RG06-017).

Competing interests None declared.

Patient consent Obtained.

Ethics approval Human ethics approval from South Sydney Western Area Health Services, Royal Prince Alfred Hospital (SSWAHS, RPAH) (approval no: X06-0045-letter dated 5 April 2006). On approval from SSWAHS, RPAH, the University of Sydney then approved our study (approval no: 9304-letter dated 16 June 2006).

Provenance and peer review Not commissioned; externally peer reviewed.

Data sharing statement No additional data are available.

Open Access This is an Open Access article distributed in accordance with the Creative Commons Attribution Non Commercial (CC BY-NC 4.0) license, which permits others to distribute, remix, adapt, build upon this work noncommercially, and license their derivative works on different terms, provided the original work is properly cited and the use is non-commercial. See: http:// creativecommons.org/licenses/by-nc/4.0/

\section{REFERENCES}

1. Mills EJ, Seely D, Rachlis B, et al. Barriers to participation in clinical trials of cancer: a meta-analysis and systematic review of patient-reported factors. Lancet Oncol 2006;7:141-8.
2. Joffe S, Cook EF, Cleary PD, et al. Quality of informed consent in cancer clinical trials: a cross-sectional survey. Lancet 2001;358: 172-7.

3. Jefford M, Mileshkin L, Matthews J, et al. Satisfaction with the decision to participate in cancer clinical trials is high, but understanding is a problem. Support Care Cancer 2011;19: 371-9.

4. Jenkins VA, Fallowfield LJ, Souhami A, et al. How do doctors explain randomized clinical trials to their patients? Europ $J$ Cancer 1999;35:1187-93.

5. Brehaut JC, Saginur R, Elwyn G. Informed consent documentation necessary but not sufficient. Contemp Clin Trials 2009;30:308-9.

6. Brehaut JC, Fergusson DA, Kimmelman J, et al. Using decision aids may improve informed consent for research. Contemp Clin Trials 2010;31:218-20.

7. Juraskova I, Butow P, Lopez AL, et al. Improving informed consent in clinical trials: successful piloting of a decision aid. J Clin Oncol 2007;25:1443-4.

8. Spiegle G, Al-Sukhni E, Schmocker S, et al. Patient decision aids for cancer treatment: are there any alternatives? Cancer 2013;119:189-200.

9. Butow PN, Dunn SM, Tattersall MHN, et al. Patient participation in the cancer consultation: evaluation of a question prompt sheet. Ann Oncol 1994;5:199-204.

10. Dimoska A, Tattersall MHN, Butow PN, et al. Can a "prompt list" empower cancer patients to ask relevant questions? Cancer 2008;113:225-37.

11. Joffe S, Cook EF, Cleary PD, et al. Quality of informed consent: a new measure of understanding among research subjects. J Natl Cancer Inst 2001;93:139-47.

12. Bergenmar M, Molin C, Wilking N, et al. Knowledge and understanding among cancer patients consenting to participate in clinical trials. Europ J Cancer 2008;44:2627-33.

13. Childs AM, Nattress K, Cox KM, et al. Presented in the program of the 5th State Cancer Nursing Research Perth, 2005.

14. Brown RF, Shuk E, Butow $P$, et al. Identifying patient information needs about cancer clinical trials using a Question Prompt List. Patient Educ Couns 2011;84:69-77.

15. Cassileth BR, Zupkis RV, Sutton-Smith K, et al. Information and participation preferences among cancer patients. Ann Intern Med 1980;92:832-6.

16. Degner LF, Sloan JA, Venkatech P. The control preferences scale. Can J Nursing Res 1197;29:21-43.

17. Fallowfield LJ, Jenkins B, Brennan C, et al. Attitudes of patients to randomized clinical trials of cancer therapy. Europ $J$ Cancer 1998;34:1554-9.

18. Spielberger CD. Manual for the state trait anxiety inventory (form $Y$ ). Palo Alto, CA: Consulting Psychologists Press, 1983.

19. Roter D. Patient participation in the patient provider interaction: the effects of patient question asking on the quality of interaction, satisfaction and compliance. Health Educ Monographs 1977;5:281-315.

20. Holmes-Rovner M, Kroll J, Schmitt N, et al. Patient satisfaction with health care decisions; the satisfaction with decision scale. Med Decis Making 1994;16:1864-6.

21. Ellis $P$, Butow PN, Simes RJ, et al. Barriers to participation in randomized clinical trials for early breast cancer among Australian cancer specialists. Aust NZ J Surg 1999;69: 505-10.

22. Ellis $\mathrm{PM}$, Butow $\mathrm{PN}$, Tattersall $\mathrm{MHN}$, et al. A randomized tria evaluating the impact of an education booklet on willingness to join randomized trials. Clin Oncol Soc Aust, Ann Sci Conf, Melbourne, 1999.

23. Clayton JM, Butow PN, Tattersall MHN, et al. Randomized controlled trial of a prompt list to help advanced cancer patients and their caregivers to ask questions about prognosis and end-of-life care. J Clin Oncol 2007;25:715-23.

24. Clayton JM, Natalia C, Butow PN, et al. Physician endorsement alone May not enhance question-asking by advanced cancer patients during consultations about palliative care. Support Care Cancer 2012;20:1457-64.

25. Stryker JE, Wray RJ, Emmons KM, et al. Understanding the decisions of cancer clinical trial participants to enter research studies: Factors associated with informed consent, patient satisfaction, and decisional regret. Patient Educ Couns 2006;63:104-9. 